\title{
Health-Related Quality of Life and Family Functioning of parents of children admitted for Cancer Treatment to a South African tertiary hospital
}

\author{
Sthembiso Tembe ${ }^{1}$, Denise Franzsen ${ }^{2}$, and Lyndsay Koch ${ }^{2}$ \\ ${ }^{1}$ Department of Basic Education \\ ${ }^{2}$ Witwatersrand Health Sciences
}

August 11, 2020

\begin{abstract}
Introduction: The aim of the study was to determine the health related quality of life (HRQoL) and family functioning of parents whose children were receiving active phase cancer treatment during a hospital admission. Methodology: A quantitative, descriptive, cross-sectional study was conducted in a specialist oncology unit within a tertiary hospital in Gauteng, South Africa. Structured interviews were conducted with the parents of children with cancer, to determine their Health Related Quality of Life (HRQoL) using the PedsQLTM Family Impact Module (2.0). Results: Twenty-Five parents participated, with ages ranging from 26 to 48 years. Most were female, with high school educational level and unemployed. Parents reported intermediate or low HRQoL particularly in the physical and worry components. Parent participants reported family functioning within the intermediate level of HRQoL. The HRQoL of parent participants in this study differed from that reported by parents in another study in a low-middle income context. Conclusion: This study indicated the diagnosis and treatment of child's cancer created challenges, which had a negative impact on parents' HRQoL and family functioning.
\end{abstract}

Health-Related Quality of Life and Family Functioning of parents of children admitted for Cancer Treatment to a South African tertiary hospital

S’thembiso Tembe, OT ${ }^{1}$, Denise Franzsen, OT $^{2}$, Lyndsay Koch OT ${ }^{2}$

${ }^{1}$ Directorate of Psychosocial and Curriculum Adaptation, Department of Basic Education, Eastern Cape, South Africa.

${ }^{2}$ Division of Occupational Therapy, School of Therapeutic Sciences, University of Witwatersrand, Gauteng, South Africa.

Text word count 4049;

Abstract word count: 173;

Key words: Childhood cancer treatment, Parents Health-related quality of life, Family Functioning

Tables: 2

Figures: 1

\begin{tabular}{ll}
\hline Abbreviations & Abbreviations \\
\hline FIM & Family Impact Module \\
HRQoL & Health Related Quality of Life
\end{tabular}




\begin{tabular}{|c|c|}
\hline Abbreviations & Abbreviations \\
\hline LMIC & Low Middle Income Countries \\
\hline PedsQL TM & Pediatric Quality of Life Trade Mark Inventories \\
\hline
\end{tabular}

\section{Hosted file}

HRQOL in parents of children with cancer Family Impact Module 2.0) ST.docx available at https://authorea.com/users/350122/articles/475041-health-related-quality-of-life-andfamily-functioning-of-parents-of-children-admitted-for-cancer-treatment-to-a-southafrican-tertiary-hospital 